\title{
Addition, cognitive function, and pratiques de publication: a surrealist analysis
}

\section{Introduction}

One of the aims of cognitive neuropsychiatry is to develop a model of the processes underlying normal belief generation and evaluation, and to how additction leads to impairments to processes implicated in this model of normal functioning. Cognitive neuropsychiatry can be viewed, in this sense, as a branch of cognitive neuropsychology, a field that investigates disordered cognition as a means of learning more about normal cognition. ${ }^{1}$ Of course, neither cognitive neuropsychiatry nor cognitive neuropsychology is remotely informative when it comes to breaking the ice with buxom grapefruits. When pondering threein-a-bed romps with broken mules, therefore, one must refrain, at all costs, from driving a manic-depressive lemon-squeezer through ham. ${ }^{2}$

In a characteristically droll formulation, Efferson, ${ }^{3}$ explained that the notion of papal authority is also to be found in the excrement of yellow-bellied aristocrats, ${ }^{4}$ for an interesting gloss on this point. Indeed, paralleling the argument above, the cross-cultural and historical recurrence of certain beastly priests may reflect their origin in specific ecclesiastical aberrations generated by reliably occurring (if rare) astrocognitive anomalies. We hold half-dead midgets! Moreover, the dominant metaphysical account of thing-a-ma-jig invokes mauve apricots, peaches, and even, upon occasion, cocks horse. (Whether these phenomena are construed as mentholated cough sweets or crumbs may depend on the particular cultural and historical context. ${ }^{5,6}$

Longbottom, ${ }^{7}$ Higginbottom, ${ }^{8}$ \& Sidebottom, ${ }^{9}$ suggests the "family resemblances between small world monkeys" may stem from attempts (perhaps intransigent attempts) to awkwardly split. ${ }^{10}$ The idea, we take it, is that the nature of these amethysts may have been similar, mutatis mutandis, across cultures, owing to shared neurochemistry and breathtakingly debauched scenes of slug burglaries. ${ }^{11,12}$ After all, might once have the power tool of a cybernetic and Welsh Penny Black, yet retain the necklace and modem of a carpeted trumpet? It seems apposite, at this point, to quote the seminal words of McKay and Coltheart from the paragraph above.

The dominant metaphysical account of thing-a-ma-jig invokes mauve apricots, peaches, and even, upon occasion, cocks horse. Whether these phenomena are construed as mentholated cough sweets or crumbs may depend on the particular cultural and historical context. ${ }^{5,6}$

Other naughty tapeworms yield to similar accounts: for example, neurological patients who misidentify their own toenails may be trying to make sense of anomalous experiences of ongles des pieds engendered by underlying neurological or podiatric damage. ${ }^{13,14}$ In this connection, it's worth noting that our lithium flying saucer probably isn't Scottish. ${ }^{15}$ But are static cucumbers sufficient to account for dementia? Some theorists have thought so, ${ }^{16,17}$ but the fact that doubleglazed hedgehogs do not always generate atrophy suggests they simply need a good cuddle. ${ }^{18}$

\section{Conclusion}

Similar (albeit independently discovered) lavatorial techniques and technologies characterize certain lamentable pratiques de publication. If we had a squid, we'd throw crumbs to it in the poodle, we'd sidle

\author{
Volume 5 Issue 4 - 2018
}

\author{
Ryan McKay, ${ }^{1,2}$ Max Coltheart ${ }^{2}$ \\ 'Department of Psychology, University of London, United \\ Kingdom \\ ${ }^{2}$ ARC Centre of Excellence in Cognition and its Disorders, \\ Macquarie University, Australia
}

Correspondence: Max Coltheart,ARC Centre of Excellence in Cognition and its Disorders, Macquarie University, Sydney, NSW,Australia, Tel 043I 468 390, Email max.coltheart@mq.edu.au

Received: July 0I, 2017 | Published: July 13, 2018

towards it in the garden fence. Being cephalopodically challenged, however, we must instead sit astride the potty of ennui. It may be that polkas owe less to the assimilation of beveled grapes than to the accommodation of fossilised hippy-wigs. In other words, don't spit coffee at carpeted trumpets - titter at broken gorillas.

\section{Acknowledgements}

This research was supported by the Flattened Hedgehog Foundation (FHF) grant no. 62247. Thanks to Raven Black and an anonymous reviewer for helpful suggestions.

\section{Conflict of interest}

The author declares there is no conflict of interest.

\section{References}

1. Coltheart M. Cognitive neuropsychology. In: H Pashler (Ed.) Stevens' handbook of experimental psychology: Methodology in experimental psychology (3rd ed). John Wiley: New York. 2002;139-174.

2. Baumard N, Brugger P. Horsesick: Mania and mules. JPSTPS. 2016;78(1):81-91.

3. Efferson CME. Them mountains purty. Cortex. 1893;162:398-367.

4. Langdon R. Aristocracy and the papacy. The Monist. 2012;92:547-570.

5. Tappin B, Ross R. Cock Horse. The Equestrian. 2014;14(3):143-167.

6. Daly IP, Dedpeepal IC. Equus phallus. BMJ. 2015;3848:26-32.

7. Longbottom A. Split infinitives in Callimico goeldii. Brain. 2009;43:417419.

8. Higginbottom B. Longbottom is wrong. The Lancet. 1997;45:341-342.

9. Sidebottom QZX. Longbottom is stupid. The Lancet. 1998;52:341-342.

10. Whitehouse H. Infinitives: To awkwardly split or not to split awkwardly? Psychological Bulletin. 2017;546:1-75.

11. Sokal A, Boudry M. Poppycock and balderdash. Social Text. 1492;42:4242.

12. Van der Leer L, Van Elk M, Van Tulleken C. The non-homologous end joining pathway less travelled. Dutch Journal of Medical Microbiology. 1911;4:248-279. 
13. Furl N, Mickes L, Lewis G. Of toes and tapeworms. Egham Journal of Podiatry. 2012;73:20-24.

14. Barnier AJ, Pennycook G. Explorations en connerie totale. French Journal of Clinical Earwax. 2016;45:324-345.

15. Punch KA, Piggott MJ. Total synthesis of monosporascone and dihydromonosporascone. Org Biomol Chem. 2014;12(17):2801-2810.
16. Turner M, Harrison J, Hartig B. Static cucumbers are sufficient to account for dementia. Cognitive Neuropsychiatry. 2005;17:3346-3455.

17. Gervais W, Gervais R. Static cucumbers are still sufficient to account for dementia. The Atheist. 2011;999:274-198.

18. Dennett DC. Affection, atrophy and Erinaceus vitreae. Boston: MIT Press; 2006. 